\title{
A EDUCAÇÃO ESCOLAR DE POMERANOS E DESCENDENTES EM SANTA MARIA DE JETIBÁ (ES)
}

\author{
Cione Marta Raasch Manske* \\ Maria Cristina Dadalto**
}

\section{RESUMO}

Este artigo investiga a educação escolar entre pomeranos edescendentes no município de Santa Maria de Jetibá (ES) a partir do processo de construção histórica deste grupo étnico no assentamento e permanência no estado. Construíram-se duas categorias de análise: a escola comunitária e a nacionalização das escolas pomeranas; o programa de educação escolar pomerano. Utilizamos o levantamento de fontes e bibliográficos, bem como análise de imagens.

Palavras-chave: educação escolar, pomeranos, Santa Maria de Jetibá.

${ }^{*}$ Universidade Federal do Espírito Santo (Ufes), Vitória/ES, Brasil.

${ }^{* *}$ Universidade Federal do Espírito Santo (Ufes), Vitória/ES, Brasil. 


\section{EDUCACIÓN ESCOLAR DE POMERANOS Y DESCENDIENTES EN SANTA MARIA DE JETIBÁ (ES)}

\section{RESUMEN}

Este artículo investiga la educación escolar entre los pomeranos y los descendientes en el municipio de Santa María de Jetibá (ES) basada en el proceso de construcción histórica de este grupo étnico en el asentamiento y la permanencia en el estado. Se construyeron dos categorías de análisis: la escuela comunitaria y la nacionalización de las escuelas pomeranas; el programa de educación escolar pomerana. Utilizamos la encuesta de fuentes y bibliografías, así como el análisis de imágenes.

Palabras clave: educación escolar, pomeranos, Santa Maria de Jetibá.

\section{SCHOOLING OF POMERANS AND DESCENDANTS IN SANTA MARIA DE JETIBÁ (ES)}

\section{ABSTRACT}

This article investigates school education of Pomerans and their descendants in the municipality of Santa Maria de Jetibá (ES) based on the historical process of building this ethnic group in the settlement and permanence in the state. Two categories of analysis were constructed: the community school and the nationalization of schools in Pomerania; the school education program in Pomerania. We used the survey of sources and bibliographies, as well as the analysis of images.

Keywords: school education, pomerans, Santa Maria de Jetibá.

\section{SCOLARITÉDES POMERANS ET DESDESCENDANTS A SANTA MARIA DE JETIBÁ (ES)}

\section{RESUME}

Cet article étudie l'éducation scolaire des Pomérans et de leurs descendants dans la municipalité de Santa Maria de Jetibá (ES) basé sur le processus historique de construction de ce groupe ethnique dans le règlement et la permanence dans l'État. Deux catégories d'analyses ont été construites: l'école communautaire et la nationalisation des écoles en Poméranie; le programme d'enseignement scolaire en Poméranie. Nous avons utilisé l'enquête sur les sources et les bibliographies, ainsi que l'analyse des images.

Mots-clés: éducation scolaire, pomérans, Santa Maria de Jetibá. 


\section{INTRODUÇÃO}

No início do Novecentos, mais precisamente em 1919, o presidente do estado do Espírito Santo (ES), Bernardino de Souza Monteiro, em mensagem dirigida ao congresso legislativo, apresentou informações e dados sobre a educação escolar, na época nomeada como instrução capixaba. Especial destaque foi dado às escolas particulares estrangeiras de imigrantes que chegaram ao estado entre meados do século XIX e início do XX. A mensagem, aponta objeção a essas escolas particulares, situadas em localidades da região montanhosa do Espírito Santo habitadas por estrangeiros ou descendentes de estrangeiros.

O problema, segundo Bernardino de Souza Monteiro (1919, p. 36-37), era que, junto com as disciplinas ministradas e impostas pela Lei 1.119, também se ensinavam idiomas alheios ao oficial. Para o presidente essa prática possibilitava a conservação de hábitos, língua e tradição dos colonos, problemática aliada ao isolamento desses grupos étnicos provocado pelo próprio poder público. Há de se ressaltar que as escolas eram regidas quase sempre por ministros das respectivas religiões dos colonos, promovendo, assim, a visão de mundo dessas religiões.

A presença das escolas e o ensino da língua imigrante contradiziam o ideário assimilacionista da cultura nacional na época. Tal concepção era compreendida como essencial para a estabilidade política e a desintegração etnocêntrica de outras culturas (KYMLICKA, 1995) no território brasileiro. A mensagem estava em sintonia com as demandas do projeto nacional que se apoiava na ampliação de um sistema escolar que difundia e legitimava o aprendizado da língua portuguesa e coibia o uso de idiomas estrangeiros (KREUTZ, 2003).

De acordo com Kreutz (2003) "eram (escolas) comunitárias, particulares e/ou pertencentes a uma congregação religiosa" e o funcionamento dessas instituições obedecia às mesmas características das escolas entre os demais grupos imigrantes no Brasil. Ao longo das duas décadas seguintes, a administração pública se empenhou na efetivação do propósito de desativar essas 
escolas. Contudo, na antiga colônia de Santa Leopoldina, atual município de Santa Maria de Jetibá, lugar onde a maioria da população era constituída por pomeranos e descendente, ${ }^{1}$ algumas dessas escolas comunitárias permaneceram em atividade.

No caso específico das escolas comunitárias da região de Santa Maria de Jetibá, elas eram conduzidas pela Igreja Luterana, profissão de fé de um número expressivo de imigrantes pomeranos e descendentes. Nas aulas aprendia-se o alemão, língua falada pelos líderes religiosos da Igreja Luterana, principais incentivadores, administradores e professores das escolas na região. Tal fato, por sua vez, ia de encontro à língua pomerana, amplamente falada no cotidiano do grupo. Mas, contraditoriamente, não havia comunicação entre falantes da língua alemã e falantes da língua pomerana, por ausência de compreensão.

A diferença na língua falada é uma das questões que emergem da relação entre pomeranos e alemães. A particularidade que envolve essa relação encontrase na história da Pomerânia, da Alemanha e do movimento imigratório. No que se refere à Alemanha, o território foi unificado apenas no final do século XIX, em 1871, período em que a imigração para o Brasil já estava em curso. Os imigrantes vindos da Alemanha agregavam culturas e dialetos diversos, caso de Hunsrück, Westfália, Württemberg e da Pomerânia (SCHULZE, 2014). Ao se estabelecerem no Brasil, esses sujeitos, em sua quase totalidade, foram registrados como alemães.

No caso específico da Pomerânia, desde o ano 6oo, período da ocupação dessa região, localizada no norte da Europa, os povos que ali habitavam falavam a língua eslava e se mobilizavam pela crença nas divindades da natureza e nos sacrifícios como forma de culto (RÖLKE, 1996). Durante séculos houve

\footnotetext{
${ }^{1}$ Para efeitos deste artigo, optamos por debater a categoria "descendente" e não "pomerano", tal como é atribuída por muitos estudiosos. Isto porque, a partir da Política Nacional de Desenvolvimento Sustentável dos Povos e Comunidades Tradicionais (PNPCT), os pomeranos no Brasil foram reconhecidos como Povo Tradicional Pomerano, e suas instituições representativas, por uma questão política e identitária, assumem a postura de se autodeclararem "pomeranos" e não "descendentes" (SPAMER, 2017).
} 
constantes disputas pelo controle do território, notadamente entre os germânicos, pelo lado ocidental e pelos eslavos, a oriente e ao sul. Durante esse processo a língua eslava foi sendo substituída pelo pomerisch, ou pomerano, língua formada a partir do Baixo-Saxão (TRESSMANN, 2005). A partir do século XII seu território esteve sob domínio de povos germânicos, brandemburgueses e prussianos, possibilitando a introdução da língua alemã e da tradição cristã.

O domínio da região não impediu que os pomeranos continuassem mantendo em seu cotidiano a crença originária e a língua pomerana em consonância com o luteranismo e o uso da língua alemã. Como a língua alemã passou a ser utilizada na aprendizagem escolar, na religião e demais instituições públicas, a língua pomerana permanecia nas atividades informais e no espaço familiar (TRESSMANN, 2005). Para o Espírito Santo os imigrantes trouxeram em suas bagagens a tradição, a língua pomerana e o luteranismo.

Após o assentamento dos imigrantes pomeranos em terras capixabas, pastores foram enviados da Alemanha para acompanhar ocotidiano dos alemães no Espírito Santo. Tal fato permitiu a introdução da escola comunitária, bem como o uso da língua alemã nos cultos e nas aulas. De acordo com Wagemann,

À frente da comunidade e dependendo de suas resoluções, está um ministro (enviado da Alemanha). Exerce sobre ela influência decisiva. É compreensível que diversos pastores cheguem a dispor de poder autocrático; o pároco não é, apenas, o pastor das almas e o predicante, mas, também, o professor, o médico e uma espécie de prefeito; enfim, é a única pessoa que possui instrução superior na comunidade (1949, p. 89-90).

Entretanto, após a implementação de políticas nacionalistas no governo Getúlio Vargas, as escolas comunitárias deram lugar à escola pública nacional. Nesse mesmo período os pastores alemães foram substituídos por brasileiros, intensificando o uso da língua portuguesa também nos cultos. Mas, apesar da proibição do uso da língua imigrante no âmbito escolar, a vivacidade da língua pomerana permaneceu firmemente presente nas práticas rotineiras econtinuou 
a fazer parte do grupo que ali habitava. Desse modo, a manutenção da língua pomerana favoreceu os membros do grupo étnico com a permanência da habitualidade, do automatismo e da semiconsciência da sua cultura (SCHÜTZ, 2010).

Foi também a manutenção da língua que possibilitou a implementação do Programa de Educação Escolar Pomerana (Proepo), em 2011, pelo município de Santa Maria de Jetibá, visando valorizar e fortalecer a cultura, a língua oral e escrita pomerana. Para Certeau e Giard (1996), a análise da cultura em sua prática e naquilo que a mantém depende de três prioridades, sendo uma delas a oralidade.

Nesse jogo performático, a educação escolar entre os pomeranos e descendentes do município assumiu prioridade. Dessa forma, este artigo intenta compreender a educação escolar entre os pomeranos e descendentes no município de Santa Maria de Jetibá (ES), com vistas a descrever e refletir sobre o processo de construção histórica desse grupo étnico no processo de assentamento e permanência no Espírito Santo.

Para a construção do texto, utilizamos especialmente o levantamento de fontes documentais no Arquivo Público do Estado do Espírito Santo, na Prefeitura Municipal de Santa Maria de Jetibá e em acervos bibliográficos. Trazemos ainda registros imagéticos.

O texto está organizado em três tópicos: primeiramente, a educação escolar: nem tanto comunitária, nem tanto nacional; Proepo: cultura, língua e identidade pomerana na educação escolar e, as considerações finais.

\section{A EDUCAÇÃO ESCOLAR: NEM TANTO COMUNITÁRIA, NEM TANTO NACIONAL}

Os pomeranos chegaram à província do Espírito Santo em meados do século XIX. Nos registros do Arquivo Público do Estado do Espírito Santo 
(FRANCESCHETTO, 2014), a indexação de muitas famílias pomeranas e de outras regiões alemãs que entraram no estado vindas da Prússia, bem como imigrantes procedentes da Renânia, Nassau, Hanover, Baviera, Hesse, Vestefália, antes da unificação, indica sua origem como alemã. ${ }^{2} \mathrm{O}$ período após a unificação da Alemanha, ou seja, entre 1871 e 1918, foi o de maior fluxo de entradas de sujeitos registrados como alemães no Espírito Santo, totalizando 2.318 imigrantes. Mas foi entre os anos de 1872 e 1873 que se deu o auge da entrada de imigrantes: 1.586 , sendo identificados, dentre esse total, predominantemente os pomeranos (1.472). Outros 694 chegaram após 1919 ou foram registrados em documentos a partir desse ano (FRANCESCHETTO, 2014).

Os imigrantes pomeranos estabelecidos no Espírito Santo eram, em sua maioria, luteranos e foram localizados inicialmente na Colônia Santa Leopoldina - lugar de terreno montanhoso, distante dos centros urbanos. Naquela tessitura também não havia estradas que pudessem viabilizar a locomoção das famílias; além disso, as casas eram situadas no meio das matas e distantes umas das outras, dificultando o relacionamento interpessoal entre as famílias. Esse contexto de adversidade de acesso inibia o contato entre os próprios imigrantes e também entre eles e os sujeitos fixados em outras localidades (ROCHA, 2000; SOARES, 1997).

Desse modo, desde o período de assentamento até o início do século XX, uma situação de quase isolamento, aliada à ausência da mediação do Estado, impulsionou entre os imigrantes pomeranos e seus descendentes a criação e o ordenamento de dispositivos sociais, econômicos e culturais com vistas à promoção de seus próprios serviços de educação e saúde. Na educação, estruturaram uma organização regulada pela religião luterana, a partir da chegada e da permanência de pastores luteranos enviados da Alemanha para comandar o campo religioso cristão.

\footnotetext{
2 O Arquivo Público do Espírito Santo reproduziu as informações conforme encontrou nas listas de navios, nas relações de entrada no porto de Vitória ou em livros de matrículas e recenseamentos das colônias (FRANCESCHETTO, 2014).
} 
Formou-se, nesse período, o vilarejo que deu origem à cidade de Santa Maria de Jetibá. A grande maioria populacional era composta de pomeranos, descendentes e algumas poucas famílias de outras regiões da Alemanha. Nessa localidade, o processo de organização educacional, fundado com base nos dogmas do luteranismo, desenvolveu-se entre o ano de 1879 - com a chegada do pastor Johannes Schäfer - até o final da década de 1960. No início, como a Igreja Luterana era a única instituição presente entre os pomeranos, opastor assumia diversas funções representativas; dentre elas, a educação escolar.

Há de se observar que na história da Igreja Luterana no Espírito Santo sempre houve uma estreita ligação entre o surgimento de comunidades e de escolas. Onde nascia uma escola nascia uma comunidade e vice-versa. O tema "escola" fazia parte da pauta de muitas reuniões e assembleias realizadas nas comunidades. Educação era uma das prioridades das comunidades que iam surgindo e se consolidando nas regiões ocupadas pelos imigrantes e seus descendentes. Tal proximidade da Igreja Luterana e da escola encontra respaldo na transcrição do relatório de Krümpel feita por Gaede (2012). Em seu breve relato a respeito das comunidades de Limoeiro-Jatibocas e São Sebastião, o pastor Erich Krümpel, que lá permaneceu até o ano de 1931, deixou registrada a situação escolar daqueles tempos:

Quando ouvimos as pessoas falarem ou quando nós mesmos ainda tivemos a oportunidade de ver qual era a situação das escolas nas colônias [dos imigrantes e de seus descendentes], como também na Comunidade em que atualmente atuo, no passado e ainda em tempos não muito distantes, e quando olhamos para a situação das escolas nos tempos atuais, quando as Comunidades luteranas já estão consolidadas, apesar das muitas carências que ainda existem, podemos constatar significativas melhorias e avanços. Quem eram estas pessoas que, no passado, se impunham como professores das crianças dos inexperientes colonos? Não se tratava apenas de colonos idosos que imigraram no século passado e que, por ainda terem algum conhecimento que trouxeram da Europa, podiam passar estes parcos conhecimentos para as crianças. Não. $\mathrm{O}$ que ainda era pior e o que não trouxe nada de proveitoso para os colonos alemães daqui era o seguinte: muitas vezes tratava-se de pessoas problemáticas e questionáveis. Na Comunidade em que atuo um médico veterinário arruinado acabou se impondo, no 


\begin{abstract}
passado, como professor. As consequências desta decadência escolar ainda são sentidas hoje em dia e significam uma luta muito grande para os Pastores de hoje [...] No início da minha atuação aqui tive que enfrentar reuniões muito agitadas quando entrava em pauta a questão escolar. Para mim ficou muito claro que, quando se tratava de melhorias e reformas, precisamos ir devagar e ter muita paciência. Assim eu insistia aonde percebia ouvidos abertos para as minhas preocupações [...] Desta maneira as coisas já melhoraram bastante na Comunidade e na escola comunitária. Certamente ainda ficará melhor. $\mathrm{Na}$ Comunidade principal temos três dias de aula por semana. A classe está dividida em três graus. Cada grau representa um ano escolar. São lecionadas as seguintes matérias: histórias bíblicas do Antigo e do Novo Testamentos, catecismo, hinos em alemão, leitura, escrita (em forma de cartas ou resumo de algum breve conto), ditado de palavras e de textos, língua (em forma de conversação) e matemática (cálculos e frações) [...] Também treino, com as crianças, o manuseio da bíblia. Os professores que atuam nas Comunidades filiais recebem de mim, por escrito, o conteúdo que deve ser passado nas aulas. Visito esporadicamente as escolas para a aplicação de provas para os alunos. [...] (GAEDE, 2012, p. 134-135).
\end{abstract}

O modelo da organização escolar era decidido em comum pelos imigrantes e descendentes em reuniões realizadas na igreja, sempre sob a mediação do pastor. A princípio, a escola comunitária pomerana, como foi nomeada, tinha uma estrutura própria. Desta forma, todas as questões que diziam respeito à estruturação do cotidiano escolar eram definidas nos encontros da igreja, como decisões acerca da contratação da professora e da frequência dos alunos nas aulas.

Os professores, além dos pastores, na maior parte dos casos eram nativos de Santa Maria de Jetibá, recebiam em espécie - quase sempre em produtos agrícolas produzidos pelos pais dos alunos - e ensinavam a língua alemã por meio de textos bíblicos. Tal configuração reafirma a organização escolar como uma demanda local intermediada pelo pastor. Sua figura continha um valor simbólico que se sobrepunha a questões de ordem prática organizacional: representava, também, um papel de comando, de sociabilidade e suporte em todas as demandas e conflitos locais (MANSKE, 2015).

Como a prática laboral entre imigrantes e descendentes incluía o trabalho 
das crianças na lavoura com os pais, a frequência dos alunos às aulas era motivo de debate para a tomada de decisão conjunta. Assim, no período inicial da criação das escolas, os alunos participavam das aulas de dois a três dias por semana, chegando a quatro ou cinco no final da década de 1960.

A ampliação do número de aulas semanais ocorreu por motivação do pastor, já brasileiro. Contudo, tal medida acabou encarecendo a manutenção da professora. Dessa forma, os pais começaram a optar por enviar seus filhos à escola pública ou por não os matricular em instituição de ensino alguma. A constatação de que uma maior quantidade de dias letivos agregava maior valor pago à escola comunitária foi o motivo pelo qual o grupo optou por aderir à proposta educacional do governo. Além disso, a estratégia de abrir escolas públicas e gratuitas junto às escolas comunitárias ampliou a adesão ao novo modelo educacional (KREUTZ, 2003).

Concomitantemente à organização dos imigrantes e de seus descendentes em Santa Maria de Jetibá, o desenrolar das décadas iniciais do século XX foi acompanhado pela implementação de políticas de valorização da cultura nacional pelo governo de Getúlio Vargas. Com a Segunda Guerra Mundial o governo intensificou seu projeto nacionalista, bem como tomou medidas de coerção contra todos aqueles rotulados como representantes do nazismo e da Alemanha.

As instituições escolares foram alvo de investidas contra o nazismo e o fascismo. No Espírito Santo é possível entender esse procedimento por meio dos estudos de Soares (1997). Segundo esse autor, em 1939 Fernando Duarte Rabelo, secretário de Educação do interventor do Estado João Punaro Bley, para justificar anacionalização das escolas, apoiava-se em memorial da década de 1920, o qual indicava a existência de provas da infiltração política pelas escolas imigrantes alemãs e italianas, bem como identificava a ação integralista ou pró-nazifascista nos livros e cadernos apreendidos (SOARES, 1997). Na Figura 1 podemos observar um dos livros que era utilizado nas escolas da região de Santa Maria de Jetibá. 
Figura 1 - Livro-texto em alemão utilizado na primeira metade do século XX.

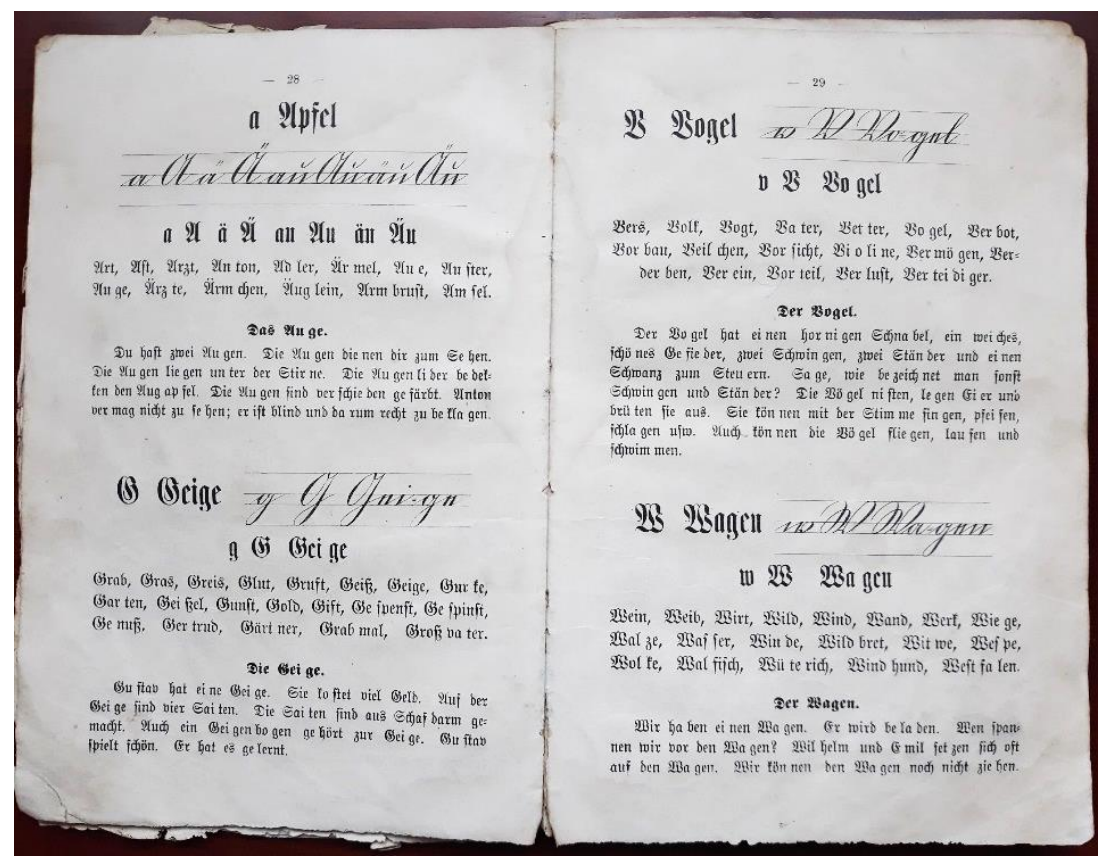

Fonte: Família Schneider/Santa Maria de Jetibá (ES).

No caso, cabe ressaltar o que esse momento desencadeou no país: prisão, perseguição, imposição da língua portuguesa em todo o território nacional, proibição do uso das línguas imigrantes e estruturação de uma educação escolar com vistas à valorização da língua e da cultura nacionais. No Espírito Santo, mereceu especial atenção e preocupação por parte do governo a manutenção da língua pomerana no interior.

Nessa tessitura, como as ações governamentais vinculadas à educação escolar almejavam a propagação e a absorção do nacionalismo entre os descendentes de imigrantes, o Espírito Santo se tornou prioridade. Em 1937, comparativamente aos outros estados em que havia escola de imigrantes alemães, o Espírito Santo alinhava-se àqueles com posição de destaque: “[...] o número de escolas da imigração alemã no Brasil era de 1.579, distribuindo-se da seguinte forma nos estados: RS com 1.041; SC com 361, SP com 61; RJ com 16; ES com 67, outros estados com 33" (KREUTZ, 2003, p. 357).

Como a continuidade da língua estrangeira representava oposição ao 
projeto do Estado, por conseguinte estabeleceu-se o objetivo imediato e necessário de desarticular as escolas particulares luteranas e o aprendizado por elas disseminado. Nesse diapasão, prioritariamente "o ensino do português nos estabelecimentos particulares tinha um alvo definido: as escolas étnicas fundadas pelos imigrantes já no tempo do Império, muitas das quais só ensinavam o idioma de origem desses grupos [...]" (VEIGA, 2007, p. 259).

Assim, em 1938 o Espírito Santo foi o segundo estado a nacionalizar as escolas imigrantes, três meses após o Paraná ter iniciado esse movimento (SOARES, 1997). No que se refere à nacionalização das escolas, Gaede afiança que o pastor Hermann Rölke registrou no Gemeindebericht (relatório comunitário), arquivo histórico da paróquia de Santa Maria de Jetibá, o seguinte fato:

O ano de 1938 será inesquecível na história da Comunidade de Santa Maria. Impôs-se uma paralisação, sim um retrocesso em todos os sentidos. Mesmo nos esforçando para entender a política de nacionalização empreendida por parte do Governo, é preciso ser dito que o golpe foi mortal para a Comunidade. No dia 18 de agosto do ano passado [1938] a nova escola que era, ao mesmo tempo, o nosso centro comunitário, cuja construção custou 25 Contos, foi desapropriada pelo Governo. Uma indenização não ocorreu até o momento. Todas as escolas comunitárias tiveram que ser fechadas por causa do decreto em vigor. O ensino religioso em língua alemã está proibido. Mas as crianças não entendem a língua portuguesa. Assim precisarão crescer sem qualquer educação religiosa. Uma assistência eclesiástica aos jovens confirmados também não nos é permitida. O Estado considera isto como uma interferência em sua tarefa educacional. A Comunidade, até agora, está aceitando tudo passivamente (GAEDE, 2012, p. 174).

Com o tempo, o conteúdo ensinado passou a obedecer a currículos unificados e à utilização de livros padronizados. Todavia, esse reordenamento desencadeou a evasão escolar das crianças pomeranas e, como consequência, o analfabetismo se tornou um problema. Também é notável como algumas localidades resistiram, permanecendo com a escola comunitária até a década de 60. Ademais, na década de 1950, mais de 70\% da população capixaba habitava o campo, onde era registrada a maior taxa de analfabetismo e também o maior 
número de professores leigos (ZUNTI, 2008). Entretanto, apesar de a língua que regia as aulas nas escolas ter passado a ser exclusivamente a portuguesa, os redutos de descendentes continuaram a falar o pomerano, principalmente nos lugares privados.

Dessa forma, a possibilidade de alterar essa configuração educacional surgiu somente após a aprovação da Constituição de 1988, com a inserção e a formalização "de princípios e garantias tendentes à declaração e efetivação dos direitos sociais" (CURY, 1997, p. 200). Foi a partir da aprovação da nova Constituição que a prefeitura de Santa Maria de Jetibá - com pesquisadores e professores locais, e também com a participação de outras instituições e sujeitos - iniciou um processo visando estruturar o ensino da língua pomerana no município. Em consequência, houve a construção de ações visando à permanência de saberes e de práticas socioculturais e simbólicas tradicionais desse grupo de descendentes de imigrantes.

Santa Maria de Jetibá conta com uma população estimada em 39.396 pessoas (INSTITUTO BRASILEIRO DE GEOGRAFIA E ESTATÍSTICA, 2017), sendo que grande parte é falante do pomerano como língua principal, numa conformação bilíngue com a portuguesa. Há muitas crianças, especialmente as residentes na zona rural, aprendendo a língua portuguesa somente na escola (BREMENKAMP, 2014; DETTMANN, 2014; KÜSTER, 2015). Mas um cenário distinto é verificado na área urbana, onde o pomerano é menos falado. No entanto, os municípios de Santa Maria de Jetibá e de Laranja da Terra são exceções aos outros 11 municípios capixabas com população de descendência pomerana (FOERSTE; PERES; KÜSTER, 2016).

Em Santa Maria de Jetibá os descendentes de imigrantes pomeranos se distinguem dentre os demais descendentes de diversos grupos imigrantes no Espírito Santo. Tal contexto se realiza por meio da manutenção de práticas socioculturais mediadas e nutridas pela língua imigrante, alimentação, rituais de casamento, relações sociais com outros membros do grupo e familiares, crenças, entre outros. 


\section{PROEPO: CULTURA, LÍNGUA E IDENTIDADE POMERANA NA EDUCAÇÃO ESCOLAR}

Município constituído principalmente por descendentes de pomeranos, em Santa Maria de Jetibá (MACENTE; SANTOS; ZANDONADE, 2009) a língua pomerana é falada entre as diversas gerações, tanto no espaço privado como no público. Também muitas das práticas socioculturais e simbólicas trazidas pelos primeiros imigrantes são mantidas vivas nas ações cotidianas por grande parte dos descendentes pomeranos. Ao se buscar compreender essa construção social, verificamos que ela é permeada por um processo fomentado pela ação da memória e da língua na passagem geracional. Da Pomerânia à atualidade, as lembranças, as permanências e os esquecimentos revelam dimensões que delineiam as relações sociais e socioculturais na contemporaneidade.

É importante ressaltar, contudo, que a valorização da língua e da cultura pomeranas no processo de escolarização foi estabelecida como projeto apenas em 2005, apesar da publicação da Lei de Diretrizes e Bases da Educação Nacional no 9.394, de 1996, a qual incumbe os municípios da organização, manutenção e desenvolvimento dos órgãos e instituições dos seus sistemas de ensino, contudo, integrando-os às políticas e planos educacionais da União e dos estados (BRASIL, 1996). Nesta direção, oreconhecimento da tradição pomerana tornou-se política pública por meio da Lei Municipal $\mathrm{n}^{0} 1.136$, de 2009, que dispõe sobre a cooficialização da língua pomerana nos espaços e repartições públicas, inclusive na educação escolar, em Santa Maria de Jetibá (SANTA MARIA DE JETIBÁ (Município), 2009).

Entretanto, a introdução de uma estrutura da língua pomerana nas aulas tornou-se um desafio, porquanto essa língua existia apenas na sua forma oral. Os dois primeiros livros com escrita pomerana foram editados somente em 2006. Esses livros, um dicionário pomerano-português e um livro que contém narrativas do cotidiano rural, tornaram-se a base para a elaboração das aulas. Para complementar, foram contratados professores que falavam o pomerano e providenciados materiais de aula, além da elaboração de uma proposta 
pedagógica que incluía a cultura de forma específica. De acordo com Manske (2015), no Proepo, há um papel de destaque ao professor bilíngue, definido como regente ou itinerante.

Como regente o professor ministra os conteúdos propostos para as aulas em pomerano e em português, tanto no Ensino Infantil quanto nos primeiros anos do Fundamental. Se não for bilíngue, o professor regente divide as aulas com o professor itinerante. Já nas séries finais do Ensino Fundamental o professor itinerante está vinculado à disciplina específica de pomerano. Neste último caso, são aulas semanais, que seguindo o padrão do programa, têm duração de uma hora (MANSKE, 2015).

Santa Maria de Jetibá contava em 2012 com 49 escolas vinculadas ao Proepo, do total de 66 implantadas no município. Dos 3.444 alunos matriculados na rede municipal no período, 2.500 eram atendidos pelo programa (SECEDU, 2012). Atabela 1, a seguir, apresenta os dados das modalidades de ensino:

Tabela 1 - Escolas e estudantes atendidos pelo Proepo, 2012.

\begin{tabular}{l|c|c|c|c}
$\begin{array}{l}\text { MODALIDADES } \\
\text { DE ENSINO }\end{array}$ & $\begin{array}{c}\text { TOTAL DE } \\
\text { ESCOLAS }\end{array}$ & $\begin{array}{c}\text { ATENDIDAS } \\
\text { PELO } \\
\text { PROEPO }\end{array}$ & $\begin{array}{c}\text { ALUNOS DA } \\
\text { REDE } \\
\text { MUNICIPAL }\end{array}$ & $\begin{array}{c}\text { ALUNOS } \\
\text { ATENDIDOS } \\
\text { PELO } \\
\text { PROEPO }\end{array}$ \\
\hline $\begin{array}{l}\text { Ensino } \\
\text { Fundamental }\end{array}$ & 41 & 31 & 2233 & 1837 \\
\hline Educação Infantil & 25 & 18 & 1211 & 663
\end{tabular}

Fonte: Secedu (2012).

Em 2013, impulsionado pela Lei $\mathrm{n}^{0}$ 1.376, de 2011, que dispôs sobre o ensino da língua pomerana oral e escrita nas escolas públicas municipais por meio do Programa de Educação Escolar Pomerana (Proepo), Santa Maria de Jetibá atingiu o atendimento universal das escolas com o ensino da cultura e da língua pomerana (SANTA MARIA DE JETIBÁ (Município), 2011). Mas a 
educação escolar prioriza ainda a apropriação da língua portuguesa e de hábitos e valores nacionais, que acontece de forma diversa entre residentes da sede e das áreas rurais. Contudo, uma peculiaridade da população do município que merece ser ressaltada é o fato de se encontrarem falantes da língua pomerana e do português, em articulação bilíngue, sejam eles descendentes de pomerano ou não descendentes.

Tal situação decorre de fatores como o intenso processo de mobilidade humana interna ocorrido no Espírito Santo a partir de meados do século XIX, a multiplicidade de grupos de imigrantes e descendentes assentados no estado, inclusive numa mesma localidade; os casamentos entre sujeitos de diferentes grupos étnicos; os movimentos que têm como suporte a circularidade de ideias e as necessidades estratégicas de realização de negócios, dentre outros motivos. Há, entretanto, em Santa Maria do Jetibá, a presença de descendentes que falam somente o português. De forma não tão comum e mais presente em encontros religiosos da Igreja Luterana, a língua alemã também se faz corrente.

Isso coloca em relevo o fato de que, em concomitância, o português e o pomerano são efetivamente empregados nas relações comerciais e de sociabilidade. Devemos considerar ainda que, além dos citadinos, o interior do município é constituído de inúmeras famílias que têm a língua pomerana como a principal. Entre essas famílias a língua portuguesa é acionada apenas em situações consideradas necessárias, como na presença de visitantes não falantes de pomerano.

O pomerano é usado entre os pomeranos, tanto da cidade quanto do campo, sendo mais frequente na zona rural, na intimidade da família, dos amigos, nas situações-limite de conflito social (luta pelos recursos e acesso à terra entre parentes e vizinhos), bem como nas acusações de bruxarias e, principalmente, nas práticas mágicas (tais como benzeções) que demarcam ritos de passagem como o nascimento, o casamento e a morte dos membros da comunidade (BAHIA, 2011, p. 102). 
A narrativa de Bahia (2011) demonstra como a manutenção da cultura trazida pelos imigrantes ainda está intimamente articulada à transmissão dos saberes e dos simbolismos que acompanham a família descendente de pomeranos. Por meio desse processo, os diversos sujeitos tecem seus discursos em dimensões multissituadas 3 (MARCUS, 1995). Nessa complexa trama dentro da qual se situam, podem se autorreconhecer e se deslocar, conforme a necessidade de construção de novos significados identitários para a própria história e mito de origem.

A família, por meio da memória social desse grupo étnico, promove e potencializa o aprendizado de práticas socioculturais e simbólicas. Entretanto, outras instituições sociais, em especial a escola, mantida pela municipalidade, contribuem com a significação dos valores trazidos pelos primeiros imigrantes. Assim, tanto a educação escolar quanto a família encontram-se num processo de entrelaçamento de ações de reconhecimento e de preservação do significado ao qual atribuem, como valor, o nexo pomerano.

No entanto, esse arranjo, situado num contexto multissituado, é mediado por práticas da população descendente e não descendente que interage continuamente nos ambientes diversos. Constitui-se, desse modo, uma complexa teia de relações que permeia o cotidiano presente nas salas de aula, nas ruas, no comércio, nos postos de saúde, bem como em outros espaços públicos e privados do município e do estado.

Em Santa Maria de Jetibá, merece destaque a construção da imagem que o descendente faz dos seus antepassados e de si mesmo na família e na escola. A reverência à memória do passado e à história pomerana, portanto, é impulsionadora desse processo de conhecimento. Desta forma, é interessante refletir sobre como se constrói uma imagem na qual passado e presente se mesclam, tendo como suporte um momento específico da história do grupo, tal

\footnotetext{
3 Para Marcus (1995), o conjunto de práticas de trabalho de campo devem ser investigados com a mesma intensidade, pois a etnografia multissituada é o resultado de conhecimento de várias intensidades e qualidades.
} 
como Pollak (1989) assegura:

O trabalho de enquadramento da memória se alimenta do material fornecido pela história. Esse material pode sem dúvida ser interpretado e combinado a um sem-número de referências associadas; guiado pela preocupação não apenas de manter as fronteiras sociais, mas também de modificá-las, esse trabalho reinterpreta incessantemente o passado em função dos combates do presente e do futuro (POLLAK, 1989, p. 910).

Na grande maioria das famílias pomeranas de Santa Maria de Jetibá as narrativas da imigração e da organização do grupo são, ainda no presente, enunciadas pelos mais idosos, que as ouviram de seus antepassados ou mesmo que tiveram tal experiência. Desse modo, vão sendo apreendidas pelos jovens como sendo a sua história. A escola, por sua vez, por meio das atividades propostas pelo Programa de Educação Escolar Pomerana, apoderou-se desse contexto e apresenta imagens e escritas pomeranas com o tema da imigração.

Pitta (2004) assegura que as imagens são organizadas por uma cultura ou indivíduo, ordenando-se sua visão de mundo tendo como suporte uma sensibilidade em interação com o meio ambiente. Ressalta, contudo, que esse ordenamento é correlacionado às características físicas do ser humano. As figuras a seguir, todas elas produzidas pela professora Mônica Gums Raasch, são parte do material de ensino pomerano em sala de aula e, igualmente, uma demonstração do projeto pedagógico em curso e da representação imagética do mundo pomerano. 
Figura 2 - Material didático utilizado nas aulas do Proepo.

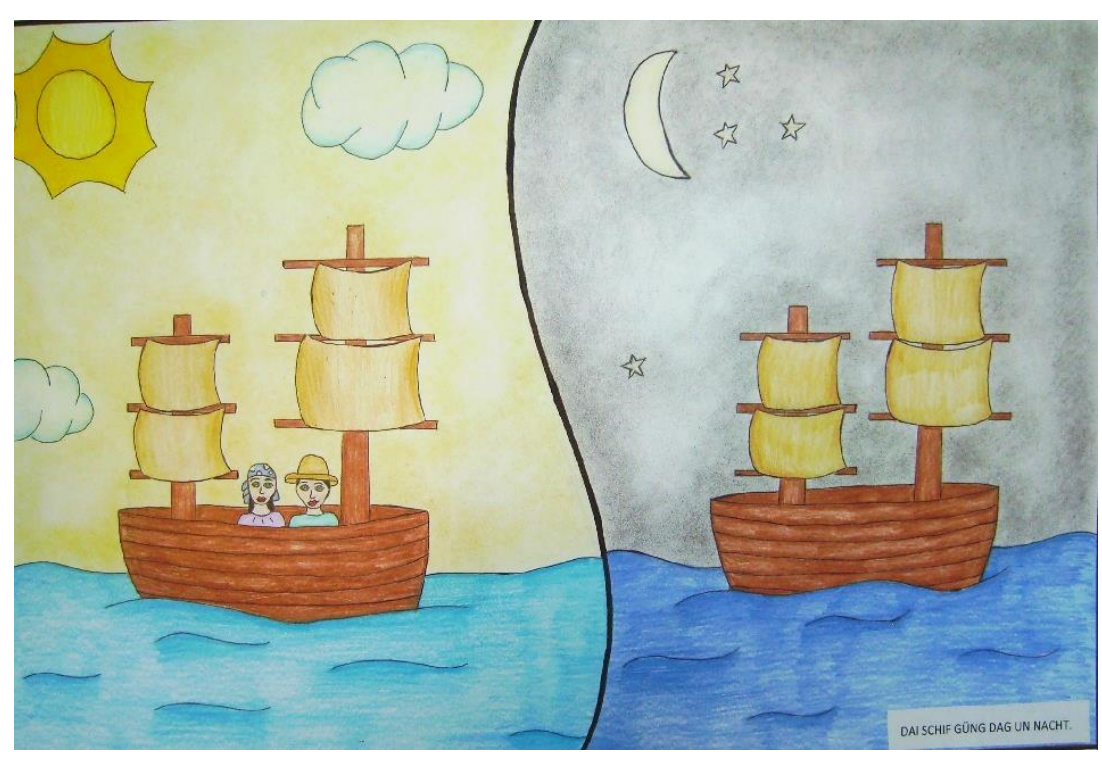

Fonte: Acervo da professora Mônica Gums Raasch.

O que se observa na Figura 2 é a construção do mito de origem da etnia pomerana a partir da história da viagem no processo imigratório para o Brasil. A construção da memória da imigração por meio da travessia em mar aberto ou turbulento em um pequeno veleiro - e, em consequência, toda a simbologia do medo, preocupação e esperança que os acompanhavam - é um dos elementos encarregados de rememorar o contexto da partida e das dificuldades vividas.

Observa-se, assim, que o aluno dá significado à cultura, às imagens e à escrita num contexto de apropriação da tradição, e, por meio da interpretação, busca-se sua manutenção. Essa prática ressalta a importância da manutenção da língua falada, da escrita, dos valores e dos hábitos nas significações do presente. Dessa forma, a identidade pomerana atribuída aos descendentes na atualidade é reproduzida num processo de reinterpretação apresentado na educação escolar.

Cabe também uma ponderação, mesmo com o papel da família e da escola no processo de recordação, é o sujeito quem assume a função de lembrar e dar significado à cultura. A proposição de Ecléa Bosi afiança que "por muito que deva à memória coletiva, é o indivíduo que recorda. Ele é o memorizador edas camadas do passado a que tem acesso pode reter objetos que são, para ele, e só para ele, 
significativos dentro de um tesouro comum" (BOSI, 1994, p. 411). Por esse motivo, é necessário manter alerta a configuração de que cada sujeito assume na organização e na representação o que é próprio de si mesmo, de seu descendente eda imagem que se constitui no processo.

Dentre os membros do núcleo familiar, vale destacar, cabe à mãe o papel de conduzir e de manter o aprendizado das práticas pomeranas. Também cabe às mães, desde a gestação e o nascimento dos filhos, até a formação de outro núcleo familiar alicerçado pelo casamento da prole, zelar pela manutenção e pela construção do significado do sujeito constituído imaginariamente como pomerano.

O pai é referência da autoridade familiar, da organização econômica e do controle do grupo. Desta maneira, associada à família, a educação escolar toma por base a disposição de reafirmar condicionantes que justifiquem as características socialmente construídas do pai e da mãe de forma tradicional. Tal elaboração se mantém independentemente do tempo presente, das questões contemporâneas de gênero, de trabalho e de outras que permeiam o cotidiano, conforme podemos observar na Figura 3.

Figura 3 - Material didático utilizado nas aulas do Proepo.

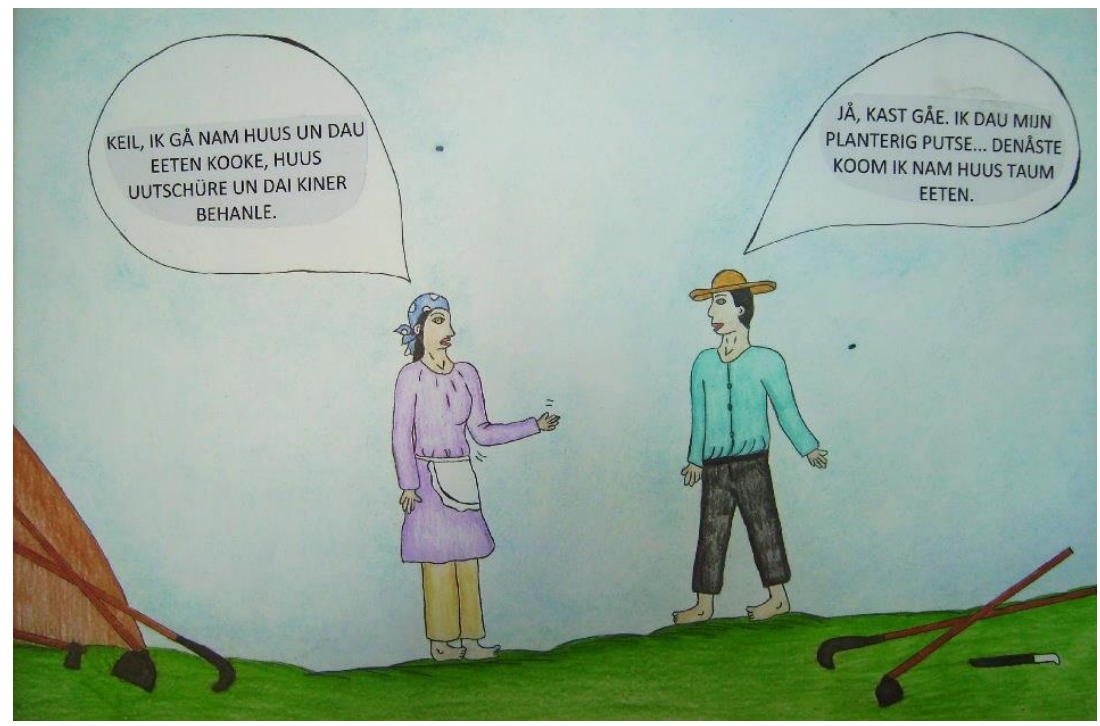

Fonte: Acervo da professora Mônica Gums Raasch. 
Nesta figura4, o contexto apresentado tem por base o dia a dia de uma família lavradora residente no interior de Santa Maria de Jetibá - o município é o maior produtor e abastecedor de hortifrutigranjeiros do estado (BAHIA, 2015). A imagem remete à ideia de um casal que utiliza as ferramentas de trabalho sem divisibilidade de função, mas também alude, de forma naturalizante, às demais atividades da mulher.

A dinâmica do trabalho familiar demonstra que "o domínio reservado às mulheres não se inscreve unicamente sob o teto de casa. As mulheres também trabalham na lavoura, fazem praticamente tudo o que os homens fazem [...]" (BAHIA, 2011, p. 61). Contudo, mesmo a mulher assumindo essa intensa atuação, é o marido a autoridade. É dele o papel de determinar as ações de todos os membros da família. Até mesmo questões como a definição da herança são estabelecidas pelo marido, demonstrando um paternalismo e uma diferenciação de gênero excludente.

Tal comportamento é ressaltado na fala do marido (Fig. 3), quando a mulher é autorizada a ir para casa cuidar de tarefas domésticas. A manutenção dessa fala na educação escolar reproduz a desigualdade das relações de gênero e, ao mesmo tempo, mantém a imagem que os descendentes de pomerano têm do pai e do marido, reafirmando essa prática cultural e simbólica na localidade.

Ainda em relação à associação da imagem da mulher e sua contribuição para a preservação das práticas socioculturais esimbólicas, não podemos retirar de tal contexto a manutenção dos hábitos alimentares vindos com os imigrantes. Na Figura 4 reproduz- se a imagem da mulher como a responsável pelo fazer e conhecer a cultura alimentar, especialmente os biscoitos e o brot - produtos muito apreciados entre os descendentes e que requerem uma receita própria pomerana. O brot é um pão tradicionalmente feito de milho e/ou inhame e/ou cará (BAHIA, 2011). A utilização da folha da bananeira, embaixo do pão e sobre a

\footnotetext{
4 - Marido, eu vou para casa e vou cozinhar a comida, lavar e cuidar das crianças.

- Sim, pode ir. Eu vou agora capinar as plantações... depois, vou para casa almoçar. Tradução: Silvana Holz.
} 
mesa, refere-se à produção do alimento tal como faziam os ancestrais. Isso é importante por afiançar a memória como elemento constituinte do sentimento de identidade (POLLAK, 1992).

Figura 4 - Material didático utilizado nas aulas do Proepo.

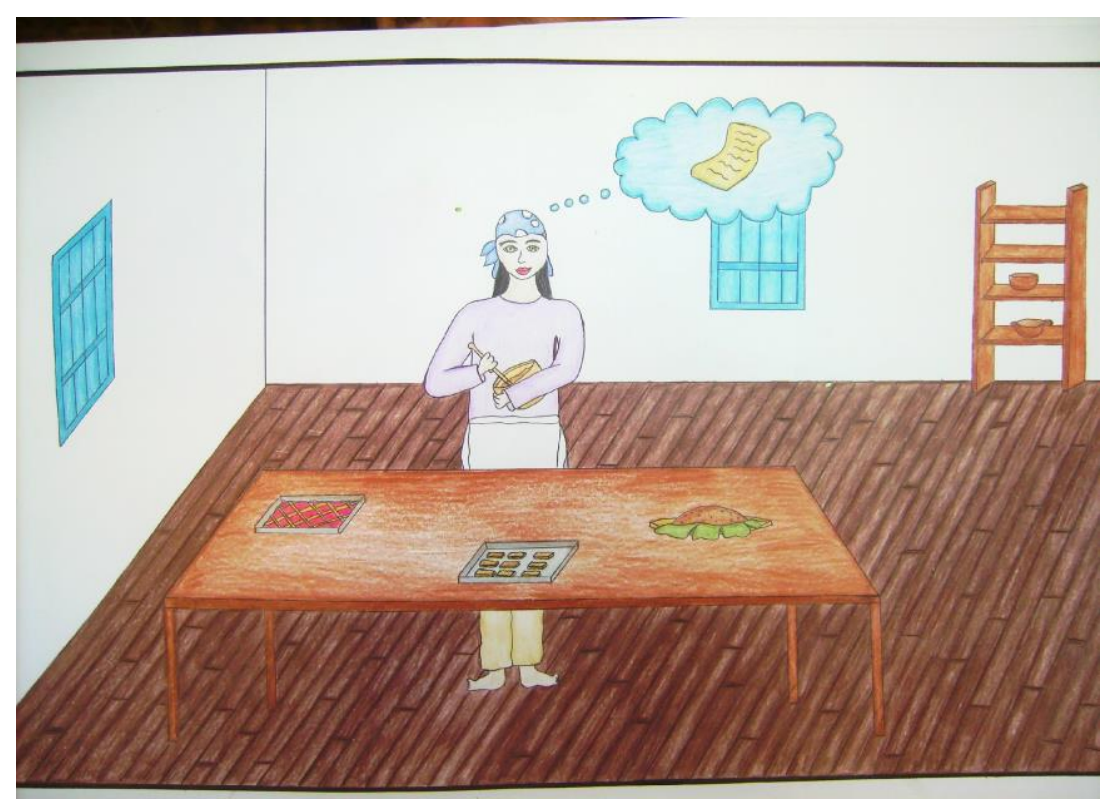

Fonte: Acervo da professora Mônica Gums Raasch.

Cabe situar que, como parte constituinte do reconhecimento da prática sociocultural e simbólica, está o apreço à agricultura. Desde a vinda dos primeiros pomeranos à contemporaneidade, possuir terras e trabalhar nelas significa um bem representativo do sentido e do sentimento de pomeranidade. $\mathrm{O}$ conhecimento vinculado à agricultura se faz presente na família e também na educação escolar (Fig. 5). 5

${ }_{5}$ Chuchu - em Recreio as pessoas plantam muito chuchu. Tradução: Silvana Holz. 
Figura 5 - Material didático utilizado nas aulas do Proepo.

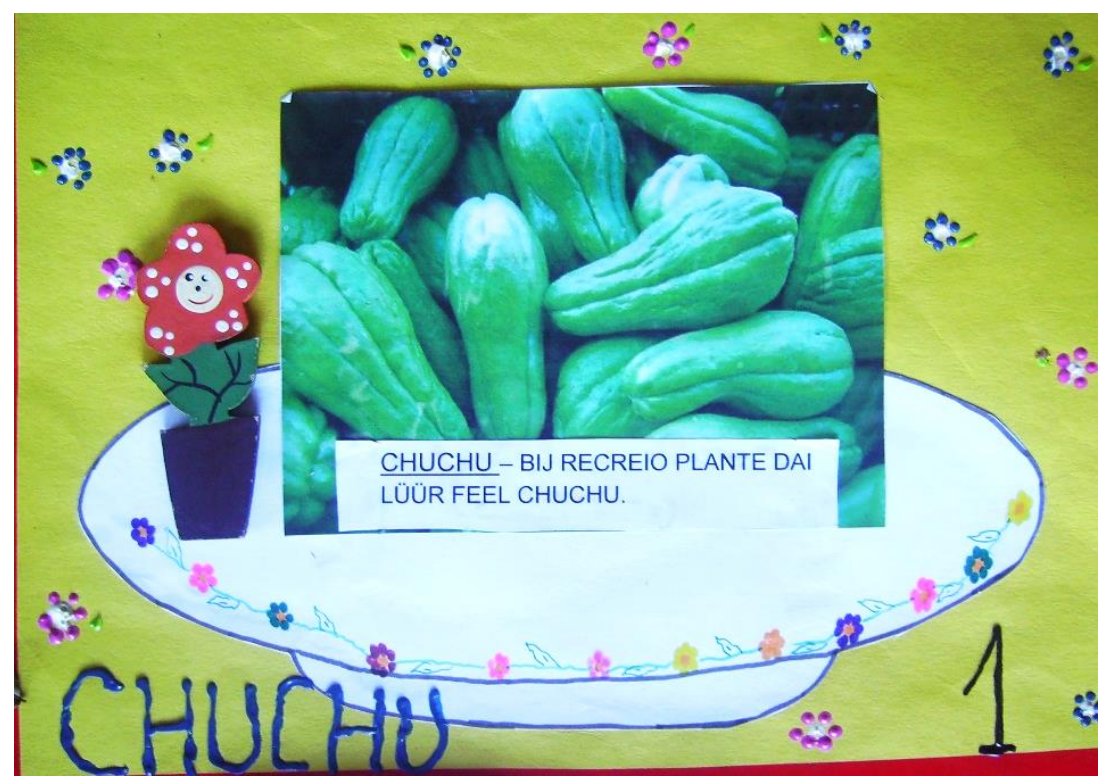

Fonte: Acervo da professora Mônica Gums Raasch.

O chuchu, produzido em diversas regiões da localidade, em especial em São Sebastião do Recreio ${ }^{6}$, é apresentado no contexto educacional como um cultivo importante, até porque a plantação de chuchu é considerada um lugar propício para jogar os cacos do ritual do quebra-louças no casamento pomerano7. Nesse rito, na sexta-feira, véspera do casamento, reúnem-se as famílias dos noivos e convidados para comer, dançar e quebrar louças. Conforme a tradição, os cacos devem ser enterrados na plantação - local onde o casal produz em parceria o alimento, com a finalidade de trazer sorte e espantar os maus espíritos. Constitui-se, assim, uma vinculação que se forma entre a terra, a produção e o simbólico.

Outro detalhe presente na Figura 5 que merece atenção é a utilização de um prato de esmalte com desenho, não muito comum na atualidade, mas que fez

\footnotetext{
${ }^{6}$ São Sebastião do Recreio é uma região de Santa Maria de Jetibá distante aproximadamente 8 $\mathrm{km}$ da sede do município.

7 Do convite à festa, o casamento é um ritual da tradição pomerana em que há o envolvimento das famílias da comunidade local. Na sexta-feira, há o quebra-louças; no sábado, o casamento na igreja reafirma a crença no cristianismo e, após a cerimônia religiosa, começam os festejos que se encerram apenas no domingo.
} 
parte da cultura pomerana. A busca da memória "[...] é uma das atividades fundamentais dos indivíduos edas sociedades de hoje, na febre e na angústia" (LE GOFF, 1994, p. 477). Neste sentido, as imagens produzidas para a educação escolar são constitutivas da memória social e simbólica da identidade pomerana na família e na escola em Santa Maria de Jetibá.

Verifica-se, assim, que o material utilizado pela professora Mônica Gums Raasch nas aulas do Proepo permite, por meio da apropriação de imagens de um cotidiano familiar, a ressignificação da língua pomerana. Nas imagens os estudantes, crianças e jovens inseridos em outro contexto daquele vivenciado por seus antepassados, se conscientizam do valor de sua própria história, aproximam a memória dos pais e avós com a atualidade e compartilham com outros estudantes, não descendentes, a sua cultura. Adere ao processo a política pública instituída no município com o Proepo, com a contratação de professores bilíngues, e a aceitação e adesão de todos os partícipes da rede de ensino ao Programa. Esses fatores são essenciais para o sucesso e continuidade do Proepo.

\section{CONCLUSÃO}

Ao descrever a trajetória da educação escolar entre os imigrantes pomeranos e descendentes em Santa Maria de Jetibá, procurou-se desvelar as intencionalidades que suscitam da escola na história do assentamento e da permanência desse grupo étnico no Espírito Santo.

A primeira educação institucionalizada entre os pomeranos e descendentes convergia com a profissão de fé da maioria do grupo, o luteranismo. Essa educação é oriunda das escolas comunitárias, que instituíram uma educação privada e religiosa, bem como o aprendizado da língua alemã, então desconhecida da maior parte do grupo. As escolas comunitárias constituíam-se ainda como uma referência para a comunidade, mediante a ausência do Estado e o distanciamento dessa população da cultura nacional. 
Em oposição às escolas imigrantes, surgem as escolas nacionalizadas com vistas à proibição das culturas imigrantes e à assimilação da língua portuguesa e da tradição nacional. Nessa disputa, sem poder competir com as leis que orientavam o estabelecimento do nacionalismo, com as imposições governamentais e a presença de escolas públicas estatais em Santa Maria de Jetibá, as atividades das escolas comunitárias foram encerradas. Sem a obrigatoriedade do ensino e mediante a proibição da língua pomerana, muitas vezes os pomeranos e descendentes optavam por não enviarem seus filhos à escola, intensificando o analfabetismo na região. Ao mesmo tempo, aprender a língua portuguesa era a anuência para o comércio, a saúde e demais atividades estatais, o que impulsionava a escolarização.

Contudo, a pesquisa permite afirmar que o uso da língua pomerana e as práticas dos descendentes que acompanham o grupo por meio da história e da memória social encarregam-se de estabelecer sua permanência no contexto de um processo contínuo de ressignificação do passado e do presente. Nesse sentido, lembramos que a memória é seletiva e éconstitutiva da identidade do grupo. Essa percepção nos orienta a destacar o papel da família pomerana nesse processo. Assim, a tradição pomerana permaneceu ao longo dos anos.

Ao mesmo tempo, as diferenças de gênero, etnia, entre outros, tornavamse motivo de discussão nos plenários legislativos nacionais. Tal procedimento permitiu o estabelecimento do Programa de Educação Escolar Pomerana (Proepo) em Santa Maria de Jetibá. Uma das ações de fundamental importância foi a construção do suporte da grafia para o aprendizado da língua pomerana, uma vez que ela existia somente na oralidade. Esse processo é elemento essencial a sustentar amanutenção da cultura e dos valores do grupo, com vistas a reafirmar permanências na localidade e também fora dela. As ações de manutenção da língua e da identidade dos imigrantes pomeranos junto a seus descendentes na educação escolar em Santa Maria de Jetibá permitem-nos entender as peculiaridades da história dessa etnia na configuração do Espírito Santo. Nessa perspectiva, consideramos, também, que a organização dos descendentes de 
pomeranos não pode ser entendida de forma excludente da estrutura social, cultural e simbólica brasileira.

\section{REFERÊNCIAS}

BAHIA, Joana. O tiro da Bruxa: identidade, magia e religião na imigração alemã. Rio de Janeiro: Garamond, 2011

BAHIA, Joana. Uma bela história a ser contada: os pomeranos no estado do Espírito Santo. In: MELO, Sandra Márcia de; SOUZA, Marcos Teixeira de (org.). Pomeranos no Brasil: olhares, vozes ehistórias de um povo. Rio de Janeiro: Letras e Versos, 2015.

BOSI, Ecléa. Memória e sociedade: lembranças de velhos. São Paulo: Companhia das Letras, 1994.

BRASIL. Lei n.o 9.394, de 20 de dezembro de 1996. Estabelece as diretrizes e bases da educação nacional. Diário Oficial [da] República Federativa do Brasil, Brasília, DF, n. 248, Seção 1, 23 dez. 1996.

BREMENKAMP, Elizana Schaffel. Análise sociolinguística da manutenção da língua pomerana em Santa Maria de Jetibá, Espírito Santo. 2014. Dissertação (Mestrado) - Universidade Federal do Espírito Santo/UFES, Vitória/ES, 2014.

CERTEAU, Michel de; GIARD Luce. Uma ciência prática do singular. In: CERTEAU, Michel; GIARD, Luce; MAYOL, Pierre. A invenção do cotidiano 2: morar, cozinhar. Tradução de Ephraim F. Alves eLúcia Endlich Orth. Petrópolis, Rio de Janeiro: Vozes, 1996.

CURY, Carlos Roberto Jamil. O Conselho Nacional de Educação e agestão democrática. In: OLIVEIRA, Dalila Andrade (org.). Gestão democrática na educação: desafios contemporâneos. Petrópolis: Vozes, 1997.

DETTMANN, Jandira Marquardt. Práticas e saberes da professora pomerana: um estudo sobre interculturalidade. 2014, $189 \mathrm{f}$. Dissertação (Mestrado em Educação) - Programa de Pós-Graduação em Educação, Universidade Federal do Espírito Santo/UFES, Vitória/ES, 2014.

ESPÍRITO SANTO (Estado). Mensagem dirigida pelo presidente do Estado do Espírito Santo Dr. Bernardino de Souza Monteiro, ao 
congresso legislativo em sua $1^{a}$ sessão ordinária da $10^{a}$ legislatura em 12 de outubro de 1919. Vitória, Imprensa Oficial, 1919.

FOERSTE, Erineu; PERES, Edenize Ponzo; KÜSTER, Sintia Bausen. Políticas linguísticas e o ensino bilíngue português-pomerano em Santa Maria de Jetibá, Espírito Santo. Matraga Estudos Linguísticos e Literários, Rio de Janeiro, v. 23, n. 38, p. 64-82, 2016.

FRANCESCHETTO, Cilmar. Imigrantes Espírito Santo: base de dados da imigração estrangeira no Espírito Santo nos séculos XIX e XX. Vitória: Arquivo Público do Estado do Espírito Santo, 2014.

GAEDE, Valdemar. Presença luterana no Espírito Santo: os primórdios da presença luterana no estado do Espírito Santo e a história da Paróquia de Santa Maria de Jetibá. São Leopoldo: Oikos, 2012.

INSTITUTO BRASILEIRO DE GEOGRAFIA E ESTATÍSTICA. Panorama: população da cidade de Santa Maria de Jetibá, Espírito Santo. Disponível em: https://cidades.ibge.gov.br/v4/brasil/es/santa-maria- de-jetiba/panorama. Acesso em: 15 jun. 2017.

KREUTZ, Lúcio. A educação de imigrantes no Brasil. In: LOPES, Eliane Marta Teixeira; FARIA FILHO, Luciano Mendes de; VEIGA, Cynthia Greive (org.). 500 anos de educação no Brasil. Belo Horizonte: Autêntica, 2003.

KÜSTER, Sintia Bausen. Cultura e língua pomeranas: um estudo de caso em uma escola do Ensino Fundamental no município de Santa Maria de Jetibá - Espírito Santo - Brasil. 2015, 255 f. Dissertação (Mestrado em Educação) Programa de Pós-Graduação em Educação, Universidade Federal do Espírito Santo/UFES, Vitória/ES, 2015.

KYMLICKA, Will. Multicultural citizenship: a liberal theory of minority rights. New York: Oxford University Press, 1995.

LE GOFF, Jacques. Memória. In: LE GOFF, Jacques. História e memória. Campinas: Editora da Unicamp, 1994,

MACENTE, Luciene Bolzam; SANTOS, Elem Guimarães dos; ZANDONADE, Eliana. Tentativas de suicídio e suicídio em município de cultura pomerana no interior do estado do Espírito Santo. J. bras. psiquiatr., Rio de Janeiro, v. 58 , n. 4, p. 238-244, 2009.

MANSKE, Cione Marta Raasch. Pomeranos no Espírito Santo: história de fé educação e identidade. Vila Velha, ES: Gráfica e Editora GSA, 2015. 
MARCUS, George. Ethnography in/of the world system: the emergence of multi-sited ethnography. Annual Review of Anthropology, Palo Alto, California, v. 24, p. 95-117, 1995.

PITTA, Daniela Perin Rocha. Imaginário, cultura, comunicação. Labirinto, n. 6, 2004. Disponível em: http://www. cei.unir.br/artigo64.html. Acesso em: 15 maio 2020.

POLLAK, Michel. Memória, esquecimento, silêncio. Estudos Históricos, Rio de Janeiro, v. 2, n. 3, p. 3-15, 1989.

POLLAK. Michel. Memória e identidade social. Estudos Históricos, Rio de Janeiro, v. 5, n. 10, p. 200-212, 1992.

ROCHA, Gilda. Imigração estrangeira no Espírito Santo: 1847-1896. Vitória: [s.n.], 2000.

RÖLKE, Helmar Reinhard. Descobrindo raízes. Aspectos geográficos, históricos e socioculturais da Pomerânia. Vitória: Ufes, 1996.

SANTA MARIA DE JETIBÁ (Município). Decreto n.o 1.136, de 26 de junho de 2009. Dispõe sobre a cooficialização da língua pomerana no município de Santa Maria de Jetibá, estado do Espírito Santo. Santa Maria de Jetibá (ES): Prefeitura Municipal, 26 jun. 2009.

SANTA MARIA DE JETIBÁ (Município). Lei n. ${ }^{\circ}$ 1.376, de 17 de agosto de 2011. Dispõe sobre o ensino da língua pomerana oral e escrita nas escolas públicas municipais através do programa de educação escolar pomerana. Santa Maria de Jetibá (ES): Prefeitura Municipal, 17 ago. 2011.

SCHULZE, Frederik. À procura de um fantasma; o imigrante alemão é um personagem fictício: debaixo desse rótulo havia grande variedade de origens, identidades e culturas. Revista de História da Biblioteca Nacional, Rio de Janeiro, Dossiê Alemães no Brasil, ano 9, n. 102, p. 20-23, março 2014.

SCHÜTZ, Alfred. O estrangeiro: um ensaio em psicologia social. Revista de Espaço Acadêmico. n. 113, ano X, out. 2010. Tradução: Márcio Duarte e Michael Hanke.

SOARES, Renato. Spini nei Fiori: a "nacionalização" das escolas dos imigrantes no Espírito Santo, na Era Vargas. Vitória: Darwin, 1997.

SPAMER, Helmar. Monumento Natural dos Pontões Capixabas: identidade pomerana na luta por direitos e território. 2017. 106 f. Dissertação (Mestrado Profissional em Sustentabilidade junto a Povos e Terras Tradicionais 
- MESPT) - Centro de Desenvolvimento Sustentável, Universidade de Brasília/UB, Brasília/DF, 2017.

TRESSMANN, Ismael. Da sala de estar à sala de baile. Estudo etnolinguístico de comunidades camponesas pomeranas do estado do Espírito Santo. 2005. 335 f. Tese (Doutorado em Lingüistica) - Programa de PósGraduação em Letras, Universidade Federal do Rio de Janeiro/UFRJ, Rio de Janeiro/RJ, 2005.

VEIGA, Cynthia Greive. História da educação. São Paulo: Ática, 2007.

ZUNTI, Maria Lícia Grossi. Entre o legal e o real - história da educação

no Espírito Santo: panorama retrospectivo da educação primária (1920/1990) e a educação de jovens e adultos (1970/1990). Linhares: Gráfica Rossi, 2008.

WAGEMANN, Ernst. A colonização alemã no Espírito Santo. Tradução de Reginaldo Sant’ana. Rio de Janeiro: Serviços Gráficos do IBGE, 1949.

CIONE MARTA RAASCH MANSKE é doutoranda em História pela Universidade Federal do Espírito Santo. Mestre em Ciências Sociais pelo Mestrado Associado (PUC-SP/UVV-ES). Pesquisadora do Laboratório de Estudos do Movimento Migratório e História Oral da Universidade federal do Espírito Santo. Estuda os pomeranos e descendentes no Espírito Santo considerando a história da imigração, a memória e a identidade.

E-mail: craaschmanske@gmail.com

(1) http://orcid.org/0000-0002-7827-3880

MARIA CRISTINA DADALTO possui Pós-Doutorado pela Università Ca `Foscari di Venezia. Doutorado em Ciências Sociais pela Universidade do Estado do Rio de Janeiro (2007). Bolsista Pesquisadora da Fundação de Amparo à Pesquisa no Espírito Santo (Fapes). Professora do Departamento de Ciências Sociais da Universidade Federal do Espírito Santo. Professora dos Programas de Pós-Graduação em História e de Ciências Sociais da Universidade Federal do Espírito Santo. Atua nas seguintes temáticas: História Oral, Memória, Identidade e Mobilidade Humana. Coordenadora do Laboratório de Estudos do Movimento Migratório e História Oral da Ufes. Membro do Laboratório de Estudos de Identidades e de Tecnociência da Ufes. 
E-mail: mcdadalto@gmail.com

(1) http://orcid.org/0000-0002-7925-3929

Recebido em: 06 de junho de 2020

Aprovado em: 28 de junho de 2020

Editora responsável: Chris Ramil

(c) (i)

Revista História da Educação - RHE

Associação Sul-Rio-Grandense de Pesquisadores em História da Educação - Asphe

Artigo de acesso aberto distribuído nos termos de licença Creative Commons. 